\title{
Sustainable Community Development Step 6: Carry Out Projects and Monitor, Evaluate and Make Adjustments as Needed $^{1}$
}

M.E. Swisher, Sandra Rezola and James Sterns ${ }^{2}$

\section{Overview}

This document explains how to evaluate your project and use sustainability indicators to measure progress. The document includes the 10 steps of the Bellagio Principles used to measure and assess progress towards sustainability.

\section{Carry Out Projects and Monitor, Evaluate and Make Adjustments as Needed}

Monitoring of sustainability indicators and project evaluation will allow you to determine whether goals and objectives are being met and to assess the short-term and long-term outcomes of your project.

Communities must be attentive and responsive to change. Through project monitoring and evaluation, new information is fed back into the community, fostering new questions and new practices. This information feedback allows communities to better adapt to changing conditions, while promoting greater long-term community stability and resilience.

A holistic approach to project evaluation will consider the results in a broad context, taking into account a project's individual, regional and even global potential effects. Using multiple evaluation methods best captures the true effectiveness of a sustainability initiative, which may be composed of several distinct program activities. Effective evaluations provide results that are understandable to community members, and can therefore be more readily channeled into the information feedback system.

Different methods exist for evaluation of a community's progress toward sustainability. The Bellagio Principles were developed in 1996 by an international group of measurement practitioners and researchers who proposed a set of criteria for measuring and assessing progress toward sustainability. One evaluation method is to assess your sustainability project in light of the Bellagio principles that follow.

1. Guiding Vision and Goals: Are the community's vision of sustainable development and the goals to attain that vision clear?

1. This document is FCS7219-Eng, one of a series of the Department of Family, Youth and Community Sciences, Florida Cooperative Extension Service, IFAS, University of Florida, Gainesville FL 32611: First published: September 2003. Reviewed by Jerry Culen, Ph.D., associate professor and Amy Simmone, Ph.D., assistant professor, Department of Family, Youth and Community Sciences, and Burl Long, Ph.D., professor, Department of Food and Resource Economics, University of Florida, Gainesville, Florida, 32611. Please visit the EDIS Web site at http://edis.ifas.ufl.edu

2. M.E. Swisher, Ph.D., associate professor, Department of Family, Youth and Community Sciences, Sandra Rezola, M.S., Institute of Food and Agricultural Sciences, and James Sterns, Ph.D., assistant professor, Department of Food and Resource Economics, University of Florida, Gainesville FL 32611. 
2. Holistic Perspective: Does the initiative consider the whole system, including social, ecological and economic sub-systems?

3. Essential Elements: Does the initiative consider equity within the current population and between present and future generations? Are the ecological components, on which life depends, considered? Is social well-being fully considered?

4. Adequate Scope: Does the time horizon that is being used capture both human and ecosystem time scales and does it reflect the needs of current and future generations? Does the spatial scale reflect both local and global sustainability?

5. Practical Focus: Are there a limited and manageable number of key issues and indicators and are measures standardized to facilitate comparisons?

6. Openness: Are data, methods and interpretation public and accessible?

7. Effective Communication: Is simplicity and clarity of structure and language emphasized?

8. Broad Participation: Were all relevant stakeholders included in the design and implementation of the project, including youth, women, minorities and disenfranchised groups?

9. Ongoing Assessment: Are goals, frameworks, and indicators adjusted as change occurs and new insights are gained?

10. Institutional Capacity: Is continuity of progress toward sustainable development supported by local institutional capacity?

In order to assess the project's long-term potential, your evaluation should include the following questions:

- How well are community leaders articulating the project's vision?

- How is the project building on the community's natural, social and physical capital?

- Was the effort collaborative and did it create new community partnerships?

- Do community members feel accountable for the project's outcomes?

\section{Reporting Evaluation Findings}

When your team is ready to report your evaluation findings, consider the resources that will be required to do so. Will you communicate successes, lessons learned and concerns visually, in brochures, as a report, or through personal communication? In Jacksonville, Florida, a report entitled "Quality of Life in Jacksonville, Indicators for Progress" is published annually to evaluate targets toward sustainability.

- Consider contacting newspapers and television and radio news stations to spread the results of the evaluation throughout the community and beyond. A poster in the community's center can display the community action plan or vision statement.

- Provide testimony from local organizations or community members about the benefits of the sustainability project. 
- Display quotes from the program participants about changes in their commitment to the community and how their actions made a difference.

- Create and present graphics like charts, pictures and computer models that illustrate changes occurring in the community.

- Develop a web site as both a sustainability education tool and a method for documenting the project's status.

- Utilize communication techniques that emphasize successes to engender community pride and encourage continued action.

As community members begin to recognize that their shared vision can indeed be realized, a change in consciousness may follow. Thereby, the community can be transformed into one in which there truly exists economic security, environmental protection, social justice, and commitment to the welfare of future generations. 